\title{
Preparation and Characterization of Paclitaxel Palmitate Albumin Nanoparticles With High Loading Efficacy: an in Vitro and in Vivo Anti-tumor Study in Mouse Models
}

\section{Hang Chen}

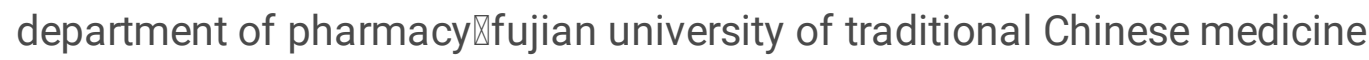

\section{Sifan Huang}

department of pharmacy $\varangle$ Fujian university of traditional medicine.

\section{Heyi Wang}

Department of pharmacy, Inner Mongonia Medical University.

\section{Xinmei Chen}

Department of pharmacy, Fujian University of Traditional Chinese Medicine.

\section{Haiyan Zhang}

Department of pharmacy, Fujian university of Traditional chinese medicine.

\section{Youfa Xu}

Shanghai Wei Er Biopharmaceutical Technology Co., Ltd.

\section{Wei Fan}

Department of pharmaceutical, seventh peoples hospital of shanghai university of traditional chinese medicine.

\section{Yun Pan}

Shanghai Wei Er Biopharmaceutical Technology Co., Ltd.

\section{Qiuyan Wen}

Shanghai Wei Er Biopharmaceutical Technology Co.,Ltd.

\section{Zhizhe Lin}

Shanghai Wei Er Biopharmaceutical Technology Co., Ltd.

\section{Xuena Wang}

Shanghai Wei Er Biopharmaceutical Technology Co., Ltd.

\section{Yongwei Gu}

Shanghai Wei Er biopharmaceutical Technology Co., Ltd.

\section{Baoyue Ding}

school of pharmacy, Jiaxing college.

\section{Jianming Chen}

Department of pharmacy, fujian university of traditional medicine. and department of pharmacy, Inner Mongolia Medical University. 


\section{Xin Wu ( $\square$ wuxin007@126.com)}

Department of Pharmacy, Fujian University of Chinese Medicine, and Shanghai Wei Er Biopharmaceutical Technology Co., Ltd

\section{Research}

Keywords: Paclitaxel palmitate, Albumin nanoparticles, Toxicity, Tissue distribution, Pharmacodynamics Posted Date: December 28th, 2020

DOl: https://doi.org/10.21203/rs.3.rs-131961/v1

License: (c) (1) This work is licensed under a Creative Commons Attribution 4.0 International License. Read Full License

Version of Record: A version of this preprint was published at Drug Delivery on January 1 st, 2021 . See the published version at https://doi.org/10.1080/10717544.2021.1921078. 


\section{Abstract}

Background: Combination of the prodrug technique with an albumin nanodrug-loaded system is a novel promising approach for cancer treatment. However, the long-lasting and far-reaching challenge for the treatment of cancers lies in how to construct the albumin nanometer drug delivery system with lead compounds and their derivatives.

Results: In this study, we reported the preparation of injectable albumin nanoparticles (NPs) with a high and quantitative drug loading system based on the $\mathrm{Nab}^{\mathrm{TM}}$ technology of paclitaxel palmitate (PTX-PA). Our experimental study on drug tissue distribution in vivo demonstrated that the paclitaxel palmitate albumin NPs (Nab-PTX-PA) remained in the tumor for a longer time post injection. Compared with saline and Abraxane ${ }^{\circledR}$ (nanoparticle albumin-bound (nab)-paclitaxel), intravenous injection of Nab-PTX-PA not only reduced the toxicity of the drug in normal organs and increased the body weight of the animals but maintained sustained release of paclitaxel (PTX) in the tumor, thereby displaying an excellent antitumor activity. Blood routine analysis showed that Nab-PTX-PA had fewer adverse effects or less toxicity to the normal organsand more importantly it inhibited tumor cell proliferation more effectively as compared with commercial Abraxane®.

Conclusions: This carrier strategy for small molecule drugs is based on naturally evolved interactions between LCFAs(Long Chain Fatty Acids) and HSA(human serum albumin), demonstrated here for PTX. Nab-PTX-PA shows higher maximum tolerated doses and increased efficacy in vivo in breast cancer models, as compared to Abraxane for FDA-approved clinical formulations. This novel injectable Nab-PTXPA platform has great potential as an effective drug delivery system in the treatment of breast cancer.

\section{Introduction}

Surgery, radiotherapy and chemotherapy remain the mainstay of treatment for malignant tumors. Although gene therapy and monoclonal antibody therapy have good therapeutic efficacy, they adapt to limited patients due to the high cost [1]. Among various chemotherapeutic drugs, PTX is the first-line drug for the treatment of breast cancer, but it may cause bone marrow suppression and hepatorenal toxicity, which reduces human tolerance to PTX. In the process of low effective dose use, drug resistance is easy to appear, leading to failure of treatment [2-5]. Therefore, how to increase the dose of PTX via a PTX delivery system with low toxicity and high effectiveness is a hot topic and a challenging issue to be solved.

Due to the low-water solubility of PTX, polyoxyethylene castor oil (cremophor EL) and ethanol are often used as solvents to prepare PTX injection. However, cremophor EL is a surfactant that can easily cause severe allergic reactions, and therefore patients need to receive corticosteroids and antihistamines as pretreatment before medication. But even so, there are still more than $2 \%$ severe allergic reactions. In addition, the use of cremophor EL makes PTX nonlinear elimination in the human body, which is not conducive to clinical safe use of drugs. 
To avoid the use of cremophor EL and reduce the toxic and adverse effects of the drug, PTX for injection (albumin binding) (Abraxane ${ }^{\circledR}$ ) was then marketed by the American Abraxis BioScience Company years ago. Studies have shown that Abraxane ${ }^{\circledR}$ can alleviate a variety of adverse reactions and allergic reactions caused by cremophor EL, and improve patient compliance and tolerance. As for poor solubility of paclitaxel itself, traditional paclitaxel preparations often exist some matter that the low stability, high particle size, high polydispersity index (PDI) and the preparation process are difficult $[6,7]$.

Our prior study found that PTX could be covalently combined with palmitic acid, forming a new compound known as PTX-PA, which could significantly improve the liposolubility of PTX. After entering the body, PTX was relea sed through esterase metabolism in tumor cells, where it exerted its anti-tumor effect. PTX-PA did not cause vascular stimulation and harm to the body during drug administration as compared with PTX alone. In addition, PTX-PA was more tolerable and could increase the dose of PTX by two fold. The experiment with PTX-PA metabolism in vivo showed that PTX-PA not only increased the dose of PTX but prolonged the time of PTX release and action.

Albumin can bind closely and reversibly with hydrophobic PTX through noncovalent bonds to realize the transport and release of the transported substances in vivo and has become a natural carrier of hydrophobic substances [8-10]. In the present study, we used albumin to prepare Nab-PTX-PA via Nab ${ }^{\text {TM }}$ technique. We found that the procedure of preparing Nab-PTX-PA was relatively simple and stable, and the particle size and the polymer dispersity index (PDI) were significantly lower than those of Abraxane ${ }^{\circledR}$. Subsequently, we further evaluated the particle size, Zeta potential, in vitro release, physical stability and loading capacity of the albumin nanoparticles (NPs). Cytotoxicity and cellular uptake of Nab-PTX-PA in 4T1 breast cancer cells in ICR mice were evaluated. In addition, tissue distribution, the anti-tumor effect and safety of Nab-PTX-PA were also evaluated.

\section{Material And Methods}

\subsection{Materials}

Materials used in this study included PTX (purity $>98 \%$; Jiangsu Yew Biotech Co., Ltd, Wuxi, China), PTXPA (purity $>97 \%$ ) and Nab-PTX-PA (our laboratory), human serum albumin (HSA, Shanghai Lloyd Blood products Co., Ltd, Shanghai,China). Abraxane ${ }^{\circledR}$ (Fresenius Kabi USA), heparin sodium (Guoyao Group Chemical Reagent Co., Ltd, Shanghai, China), and Coumarin 6 (Aladdin Reagent Platform), CCK-8 and DMSO (Sigma-Aldrich, Shanghai). All other solvents were of chromatographic grade and other chemicals were of analytical grade. Twenty-four female ICR mice weighing $18 \pm 2 \mathrm{~g}$ (Second Military Medical University, Shanghai, China) were housed at $25 \pm 2{ }^{\circ} \mathrm{C}$ with relative humidity at $47.5 \pm 2.5 \%$. All animal procedures were performed in accordance with the Ethical Guidelines for Investidations in Laboratory Animals issued by the Second Military Medical University.

\subsection{Preparation of the albumin NPs and drug loading}


The preparation method of Nab-PTX-PA for injection was as follows: The organic phase was prepared with the prescription volume PTX-PA absolute chloroform and anhydrous ethanol. $12.5 \mathrm{~mL}$ HSA was mixed with disdtilled water and put into a constant temperature tank as aqueous phase. When its temperature dropped to $0^{\circ} \mathrm{C}$, the organic phase was added to the shearing machine by continuous stirring and dispersing the water phase, and the colostrum was obtained by shearing $1 \mathrm{~min}$ at $10000 \mathrm{r} / \mathrm{min}$ stirring, which was homogenized and emulsified by using a high pressure homogenizer to obtain NabPTX-PA. The organic solvent was removed by ultrafiltration, and then separately packaged, freeze-dried and cap-sealed to obtain its lyophilized products.

\subsection{Characterization of the albumin NPs}

The particle size and PDI of the formulation were measured with a Zetasizer laser particle size analyzer (Malven, UK). In addition, the morphology of the preparation was characterized by transmission electron microscopy (TEM) via negative staining. The sample preparation for TEM photography was as follows: Nab-PTX-PA solution was dripped on the surface, let settle into the carbon-sprayed copper mesh, negatively stained with $2 \%$ phosphotungstic acid for $3 \mathrm{~min}$, and dried naturally in high resolution. The morphology of Nab-PTX-PA was observed by TEM.

\subsection{Stability study}

The physical stability of PTX-PA loaded albumin NPs was examined in a sealed and dark condition at $4^{\circ} \mathrm{C}$. Briefly, at different intervals $(0,4,12$ and 24 weeks post-preparation), samples from albumin NP formulations were regularly collected at the designated time points to evaluate the physical stability, particle size, encapsulation efficacy (EE), morphology, PTX-PA leakage and the tendency to form sedimentation. The particle size and surface charge were calculated using Malven. Also, the leakage ratio of PTX from each albumin NP formulation was calculated as EE\% during 6 months, and compared with that of the same albumin NPs at the beginning of the experiment (time 0 ).

\subsection{Drug release experiments}

The release kinetics of paclitaxel palmitate in albumin NPs was quantitatively detected by drug release experiments. $1 \mathrm{~mL}$ Nab-PTX-PA was mixed with $200 \mathrm{~mL}$ release buffer solution (10\% ethanol, pH5.5). Samples collected at various time points were dissolved by paddle stirring at a rotation speed of $100 \mathrm{rpm}$, and the concentrations of the entrapped drugs were determined after removing the released drug by filter membrane filtration. The sample solution $(100 \mu \mathrm{L})$ was absorbed in a $1.5 \mathrm{~mL}$ centrifuge tube, and the protein was precipitated with $300 \mu \mathrm{L}$ acetonitrile. After 1-min vortex mixing, the sample was centrifuged at $13000 \mathrm{rpm}$ for $10 \mathrm{~min}$.

\subsection{In vitro plasma conversion}

Nab-PTX-PA freeze-dried powder $(1.598 \mathrm{mg})$ was weighed in the cylinder, dissolved with $2 \mathrm{~mL}$ SD rat blank plasma (PTX-PA concentration $100 \mu \mathrm{g}-\mathrm{mL}^{-1}$ ), and centrifuged at low speed of $100 \mathrm{rpm}$ per minute, in a shaker $37^{\circ} \mathrm{C}$ shock incubation. $100 \mu \mathrm{L}$ plasma was collected via the tail vein at $0,1,3,5,7,9$, 12, 24 and $30 \mathrm{~h}$ after treatment of the plasma samples to determine the PTX content. 


\subsection{Maintenance of cell lines}

Mouse breast cancer 4T1 cells were kindly provided by Stem Cell Bank of the Chinese Academy of Sciences (Shanghai China) and cultured in DMEM medium, and maintained in the $5 \% \mathrm{CO}_{2}$ atmosphere in a humidified incubator at $37^{\circ} \mathrm{C}[11]$.

\subsection{Cytotoxicity assay}

Cytotoxicity of different formulations was measured by CCK-8. 4T1 cells were seeded in 96 well plates at a density of $5 \times 10^{3}$ cells per well, pre-cultured in a $37{ }^{\circ} \mathrm{C}$ and $5 \% \mathrm{CO}_{2}$ incubator for $24 \mathrm{~h}$, treated with a series of Nab-PTX-PA and Abraxane ${ }^{\circledR}$ working solutions, and incubated at $37{ }^{\circ} \mathrm{C}$ for additional $48 \mathrm{~h}$. After adding $10 \mu \mathrm{L}$ CCK-8 in each well, incubation was continued for $2 \mathrm{~h}$. Absorbance was measured at $570 \mathrm{~nm}$ and the mean value was used for analysis. The cell survival rate was calculated using the following equation [12-14]:

Cell survival rate $(\%)=[(A s-A b) /(A c-A b)] \times 100 \%$.

Label: As: experimental hole (culture medium containing cells, CCK-8 reagents, drugs). Ab: blank pore (medium without cells and drugs, CCK-8 reagent. Ac: control hole (cell-only medium and CCK-8 reagent).

\subsection{In vitro cell uptake}

Albumin NP uptake assay was performed by flow cytometry. 4T1 cells were plated with $100 \mu \mathrm{L}$ Coumarin 6, Nab-PTX-PA and Abraxane® fluorescent NPs and incubated for $4 \mathrm{~h}$ [15]. The culture medium was centrifuged at $1000 \mathrm{r} / \mathrm{min}$ for $5 \mathrm{~min}$. The supernatant was removed by $1 \mathrm{~mL}$ PBS centrifugation for two times and then mixed with $500 \mu \mathrm{L}$ PBS. The mean fluorescence intensity of 10000 cells was calculated by using a $527 \mathrm{~nm}$ passband filter FL1-H to detect green fluorescence at $490 \mathrm{~nm}$ by flow cytometry, and changes in size of the PTX-PA fluorescent albumin NPs and Abraxane ${ }^{\circledR}$ fluorescent NPs were measured using a Malvern particle size analyzer [16, 17].

\subsection{Tissue distribution assay}

Thirty-six ICR mice were randomly divided into two groups and injected with Abraxane ${ }^{\circledR} 20 \mathrm{mg} / \mathrm{kg}$ and Nab-PTX-PA $25.58 \mathrm{mg} / \mathrm{kg}$ via the tail vein [18]. Mice were sacrificed at 0.5, 1, 4, 8, 24 and $48 \mathrm{~h}$ post injection. Blood samples and tissues including the heart, liver, spleen, lung, kidney and tumor were collected and weighed at 1,4 and $24 \mathrm{~h}[19,20]$. Tissue samples were prepared at a 1:3 (w/w) ratio with normal saline (NS) and ground in a high-speed homogenizer into homogenates. $100 \mu \mathrm{L}$ tissue homogenate was transferred into a $1.5 \mathrm{~mL}$ centrifuge tube, and protein was precipitated with $300 \mu \mathrm{L}$ acetonitrile containing internal standard liquid [21,22]. The supernatant was vortically mixed for $1 \mathrm{~min}$ and centrifuged at $13000 \mathrm{r} / \mathrm{min}$ for $10 \mathrm{~min}$, from which $150 \mu \mathrm{L}$ supernatant was mixed with $300 \mu \mathrm{L} 30 \%$ acetonitrile and prepared into a $5 \mu \mathrm{L}$ sample injection [23].

\subsection{In vivo antitumor effects}


4T1 cells of logarithmic growth were diluted by addition of an appropriate amount PBS and injected into the right axilla of the ICR mice at a $0.2 \mathrm{~mL}$ concentration of about $1 \times 10^{7} / \mathrm{mL}$ of $4 \mathrm{~T} 1$ cell suspension. ICR mice were inoculated with $\sim 10^{7} 4 \mathrm{~T} 1$ cells on the right flank, and treatments began when average animal tumor burden was between 50 and $150 \mathrm{~mm}^{3}$.

Twenty-four tumor-bearing ICR mice were equally randomized into four groups receiving $0.2 \mathrm{~mL} N$, Abraxane ${ }^{\circledR}(20 \mathrm{mg} / \mathrm{kg})$, Nab-PTX-PA (25.58 mg/kg) and double-dose Nab-PTX-PA $(51.16 \mathrm{mg} / \mathrm{kg})$ through the tail vein once every other day, totaling four times. Each mouse tumor volume was calculated according to $\left(a^{2} \times b\right) / 2$ formula(the short diameter (a) and long diameter (b) ). The relative tumor volume was calculated according to the RTV $=V_{t} / V_{0}$ [24], where the tumor volume was $V_{0}$ when randomly grouped, and the tumor volume at each measurement was $V_{t}, 24 \mathrm{~h}$ after the mice were weighed and sacrificed. The tumor inhibition rate and relative tumor proliferation rate were calculated according to the following formula:

relative tumor proliferation rate $=\frac{\text { RTV of administation group }}{\text { RTV of control group }} \times 100 \%$

\subsection{Safety evaluation}

\subsubsection{Blood routine examination}

In the pharmacodynamics experiment, after $24 \mathrm{~h}$ when ICR mice were last intravenously (IV) administered, and $0.5 \mathrm{~mL}$ whole blood was drawn from the orbit of the ICR tumor-bearing mice with a trace capillary needle and treated with the anticoagulant for blood routine counting, including white blood cell (WBC), hemoglobin (HGB), red blood cell (RBC), neutrophil (Neut) and platelet (PLT) [25].

\subsubsection{Blood biochemical test}

After the last $24 \mathrm{~h}$ pharmacodynamics, $0.5 \mathrm{~mL}$ anticoagulant-treated whole blood from the ICR tumorbearing mice was collected in a dry tube. Albumin (ALB), total bilirubin (TBIL), alanine aminotransferase (ALT), alanine aminotransferase (AST), creatinine (CRE), urea nitrogen (UN) and creatine kinase (CK) were the main indexes for blood biochemical detection.

\subsection{Statistical analysis}

Data were statistically analyzed using GraphPad Prism (version 6, San Diego, US) and SPSS22 software. All studies were repeated three times and all measurements were carried out in triplicate. Results are reported as the mean \pm standard deviation (SD). C was tested by factor analysis of variance. Differences between experimental groups were considered significant when the P-value was less than 0.05 . 


\section{Results}

\subsection{Physicochemical characterization of albumin NPs of PTX-PA}

According to TEM, the appearance of Nab-PTX-PA was spherical and evenly distributed. Its particle size was $87.63 \pm 1.15 \mathrm{~nm}$, with a single peak of $0.185 \pm 0.009$ and a Zeta potential of $11.7 \pm 0.61 \mathrm{mV}$. The typical particle size distribution and Zeta potential are shown in Fig. 2.

\subsection{Stability test}

The stability of PTX palmitate solution under $4^{\circ} \mathrm{C}$ conditions is shown in Fig. 3 . The results showed that the content of three different concentrations of PTX-PA solution under $4^{\circ} \mathrm{C}$ conditions remained basically unchanged with good stability in one month could be used as a reserve solution in the process of preparation optimization.

Table 1

The Encapsulation rate of Nab-PTX-PA $(n=3)$

\begin{tabular}{|c|c|c|c|c|}
\hline Time & $C_{0}(\mu \mathrm{g} / \mathrm{mL})$ & $\mathrm{C}_{1}(\%)$ & $\mathrm{EE}(\%)$ & Mean \pm SD \\
\hline 1 & 6.49 & 0.13 & 98.17 & $97.71 \pm 0.49$ \\
\hline 2 & 7.21 & 0.15 & 97.90 & \\
\hline 3 & 7.31 & 0.21 & 97.01 & \\
\hline
\end{tabular}

\subsection{Drug release experiments}

Using the dissolution method, the mixed solution of ethanol and PBS, after adjusting the pH value to 5.5, was used as the dissolving medium. The release of Nab-PTX-PA was due to what properties of albumin occurred change in ethanol, and destroyed the structure of albumin nanoparticles. By analogy with the release of Nab-PTX-PA in different concentrations of ethanol, the release rate of two media (PBS (pH 5.5) and the mixed solution (pH5.5) of $10 \%$ ethanol and PBS) was found to be relatively superior. In the mixed solution ( $\mathrm{pH} 5.5$ ) of $20 \%$ ethanol and PBS, the release rate of Nab-PTX-PA reached over $90 \%$ at $2 \mathrm{~h}$ but the release rate of the drug was too fast. The release rate of PBS (pH5.5) at $4 \mathrm{~h}$ was about $50 \%$, showing relative stability in Fig. 4. In the mixed solution (pH5.5) of $20 \%$ ethanol and PBS, the release rate of NabPTX-PA reached $90 \%$ and remained stable for $6 \mathrm{~h}$. In both media, the release rate of Nab-PTX-PA was satisfactory and there was no obvious release acceleration.

\subsection{In vitro plasma transformation}

Figure 5 shows the cumulative conversion rate in rat plasma in Nab-PTX-PA at $30 \mathrm{~h}$ and the concentration of PTX. The results showed that about $18.35 \%$ Nab-PTX-PA was released from $0 \mathrm{~h}$ to $30 \mathrm{~h}$, indicating that 
the active drug PTX could be released slowly in rat plasma, which laid the foundation for subsequent animal experiments in vivo.

\subsection{Cytotoxicity assay}

The cytotoxicity of Nab-PTX-PA and Abraxane was investigated by CCK-8 assays with 4T1 cells. As shown in Fig. 6 and Table 2, the survival rate of 4T1 cells in different concentrations of Nab-PTX-PA was higher than that in Abraxane ${ }^{\circledR}$. Table 2 shows that the $\mathrm{IC}_{50}$ of Nab-PTX-PA was about 30 times that of Abraxane ${ }^{\circledR}$. In addition, Abraxane ${ }^{\circledR}$ and Nab-PTX-PA both had concentration-dependent toxicity, and the toxicity of Nab-PTX-PA was lower than that of Abraxane ${ }^{\circledR}$ at the same concentration (Fig. 6).

Table 2

The $\mathrm{IC}_{50}$ of Abraxane ${ }^{\circledR}$ and Nab-PTX-PA

\begin{tabular}{|lll|}
\hline Cell line & $\mathrm{IC}_{50}(\mu \mathrm{M})$ & \\
\cline { 2 - 3 } & Abraxane® & Nab-PTX-PA \\
\hline 4T1 & 3.249 & 103.7 \\
\hline
\end{tabular}

\subsection{Cell uptake}

The cell uptake experiment showed that the fluorescence intensity of Nab-PTX-PA and Abraxane® cells was higher than that in Coumarin 6 group, demonstrating that both Nab-PTX-PA and Abraxane ${ }^{\circledR}$ could improve $4 \mathrm{~T} 1$ cell uptake. The PTX-PA uptake $4 \mathrm{~h}$ after Nab-PTX-PA was lower than that of Abraxane®, indicating that the Nab-PTX-PA entry process was slow and long-lasting as compared with Abraxane ${ }^{\circledR}$.

Table 3

The mean fluorescence value of each group

\begin{tabular}{|llll|}
\hline Test tube name & Number of particles & Total (\%) & Mean FITC-A \\
\hline Blank cell Group & $1 \times 10^{4}$ & 100.00 & 30629.6 \\
\hline Coumarin 6 Group & $1 \times 10^{4}$ & 100.00 & 174358.4 \\
\hline Nab-PTX-PA Fluorescence Group & $1 \times 10^{4}$ & 100.00 & 2187230.5 \\
\hline Abraxane® Fluorescence Group & $1 \times 10^{4}$ & 100.00 & 3448224.3 \\
\hline
\end{tabular}

\subsection{Biodistribution}

The drug concentration-time distribution in the tumor-bearing mice is shown in Fig. 8. the PTX of Abraxane ${ }^{\circledR}$ was almost stored in the liver and kidney, and the concentration of it for which in the tumor 
site was relatively little, and the drug concentration gradually decreased with time. Figure 8B shows PTXPA concentration change in each tissue after caudal vein injection. The result showed that PTX-PA was mainly distributed in the liver, spleen and kidney. Figure 8D shows a slow increase in PTX-PA at the tumor site. This might be due to the tumor enhanced permeability and retention (EPR) effect, which caused slow entry of Nab-PTX-PA into the tumor. Figure 8C shows drug distribution of PTX metabolized in the heart, liver, spleen, lung and kidney of the tumor-bearing mice. The result showed that the concentration of metabolic PTX distributed across all tissues less than Abraxane ${ }^{\circledR}$, as well as the metabolic PTX of NabPTX-PA less than Abraxane ${ }^{\circledR}$ about which the toxicity for tissues. Figure 8D shows intuitive comparison of distribution of Abraxane ${ }^{\circledR}$ and PTX-PA metabolized PTX in the tumor site. The result showed that the concentration of PTX in Abraxane ${ }^{\circledR}$ decreased gradually with time, The PTX concentrations of metabolized PTX-PA increased over time, proving that PTX-PA could release active drug PTX slowly at the tumor site and stay in the tumor for a long time to play an anti-tumor role.

\subsection{Antitumor study}

As shown in Table 4, Abraxane® $(20 \mathrm{mg} / \mathrm{kg})$, Nab-PTX-PA $(25.58 \mathrm{mg} / \mathrm{kg})$ and Nab-PTX-PA $(51.16 \mathrm{mg} / \mathrm{kg})$ had different anti-tumor effects. The tumor inhibition rate of $25.58 \mathrm{mg} / \mathrm{kg}$ and $51.16 \mathrm{mg} / \mathrm{kg} \mathrm{Nab-PTX-PA}$ was higher than that of Abraxane ${ }^{\circledR}(20 \mathrm{mg} / \mathrm{kg})$, with the tumor inhibition rate of $51.16 \mathrm{mg} / \mathrm{kg}$ Nab-PTXPA being more significant. Figure 9A shows that the tumor volume in the two Nab-PTX-PA groups decreased with time, and this decreasing trend was more significant in $51.16 \mathrm{mg} / \mathrm{kg} \mathrm{Nab-PTX-PA} \mathrm{group.}$ Figure 9B shows the change in body weight of the tumor-bearing mice during drug administration. The results showed that the mouse weight in $25.58 \mathrm{mg} / \mathrm{kg}$ and $51.16 \mathrm{mg} / \mathrm{kg} \mathrm{Nab-PTX-PA} \mathrm{groups} \mathrm{was} \mathrm{slightly}$ elevated or remained basically unchanged, indicating that Nab-PTX-PA had fewer adverse effects as compared with the group of Abraxane ${ }^{\circledR}(20 \mathrm{mg} / \mathrm{kg})$.

Table 4

Antitumor effect of Nab-PTX-PA in the mouse breast cancer 4T1 model in terms of tumor weight ( $\overline{\mathrm{X}} \pm \mathrm{s}, n$ =6)

\begin{tabular}{|lllll|}
\hline group & $\begin{array}{l}\text { experimental } \\
\text { animal }\end{array}$ & $\begin{array}{l}\text { Tumor } \\
\text { weight }\end{array}$ & $\begin{array}{l}\text { Tumor } \\
\text { suppressor }\end{array}$ & $\begin{array}{l}\text { Relative tumor } \\
\text { proliferation rate }\end{array}$ \\
\cline { 2 - 4 } & $\begin{array}{l}\text { Start/End } \\
\text { (number) }\end{array}$ & $\mathbf{( g )}$ & $\mathbf{( \% )}$ & $\mathbf{( \% )}$ \\
\hline Saline & $6 / 6$ & $0.42 \pm$ & - & - \\
\hline Abraxane® & $6 / 6$ & 0.23 & & 64.08 \\
\hline $\begin{array}{l}\text { Nab-PTX- } \\
\text { PA(25.58 mg/kg) }\end{array}$ & $6 / 6$ & $0.22 \pm$ & 47.62 & 50.61 \\
\hline $\begin{array}{l}\text { Nab-PTX- } \\
\text { PA(51.16 mg/kg) }\end{array}$ & $6 / 6$ & $0.15^{*}$ & & \\
\hline
\end{tabular}




\subsection{Blood routine examination}

Table 5 shows single factor ANOVA analysis of the blood routine data using SPSS 22.0 software. Compared with NS group, the number of blood cells in the drug administration groups decreased in varying degrees. WBC (white blood cell) and RBC (red blood cell) were associated with myelosuppressive toxicity. Compared with Abraxane ${ }^{\circledR}(20 \mathrm{mg} / \mathrm{kg})$ group, the number of $\mathrm{WBC}$ and RBC were increased in which Nab-PTX-PA group $(25.58 \mathrm{mg} / \mathrm{kg}$ ) and Nab-PTX-PA $(51.16 \mathrm{mg} / \mathrm{kg})$ group, and statistically significant $(P<0.05)$. Neutropenia was a common adverse reaction of Abraxane ${ }^{\circledR}$. Table 5 shows that the Neut of $25.58 \mathrm{mg} / \mathrm{kg}$ Nab-PTX-PA group was significantly improved as compared with $20 \mathrm{mg} / \mathrm{kg}$ Abraxane® group.

Table 5

Comparison of blood parameters indicating the anti-tumor effect of Nab-PTX-PA in mouse 4T1 cells ( $\overline{\mathrm{x}} \pm$ $\mathrm{s}, n=6)$

\begin{tabular}{|c|c|c|c|c|c|}
\hline \multirow[t]{2}{*}{ Group } & WBC & RBC & PLT & Neut\# & HGB \\
\hline & $\left(\times 10^{9} \mathrm{~L}^{-1}\right)$ & $\left(\times 10^{12} L^{-1}\right)$ & $\left(\times 10^{9} \mathrm{~L}^{-1}\right)$ & $\left(\times 10^{9} \mathrm{~L}^{-1}\right)$ & $(g / L)$ \\
\hline Saline & $\begin{array}{l}19.54 \pm \\
4.04\end{array}$ & $9.34 \pm 0.19$ & $829.67 \pm 19.86$ & $17.22 \pm 4.73$ & $\begin{array}{l}15.20 \pm \\
0.10\end{array}$ \\
\hline Abraxane ${ }^{\circledR}$ & $4.01 \pm 0.35$ & $\begin{array}{l}8.38 \pm \\
0.27^{\star \star}\end{array}$ & $290.33 \pm 52.54^{\star \star \star}$ & $1.09 \pm 0.17^{\star \star \star}$ & $\begin{array}{l}14.00 \pm \\
0.26^{*}\end{array}$ \\
\hline $\begin{array}{l}\text { Nab-PTX-PA } \\
(25.58 \mathrm{mg} / \mathrm{kg})\end{array}$ & $\begin{array}{l}14.26 \pm \\
2.08^{\&}\end{array}$ & $\begin{array}{l}9.18 \pm \\
0.21^{8 \&}\end{array}$ & $353.67 \pm 44.41^{\star \star \star}$ & $8.97 \pm 0.90^{\star \star, \& \&}$ & $\begin{array}{l}14.53 \pm \\
0.68\end{array}$ \\
\hline $\begin{array}{l}\text { Nab-PTX-PA } \\
(51.16 \mathrm{mg} / \mathrm{kg})\end{array}$ & $\begin{array}{l}6.64 \pm \\
0.17^{\text {\&\& }}\end{array}$ & $\begin{array}{l}9.17 \pm \\
0.24^{8 \&}\end{array}$ & 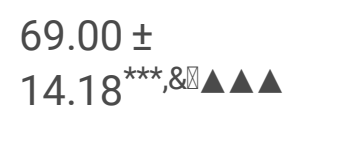 & $\begin{array}{l}2.24 \pm \\
0.33^{\star \star \star}, \mathbf{\Lambda} \Delta\end{array}$ & $\begin{array}{l}14.63 \pm \\
0.21\end{array}$ \\
\hline $\begin{array}{l}\text { label a:Compar } \\
\text { label b:Compar } \\
\text { label c:Compari }\end{array}$ & $\begin{array}{l}\text { on with nega } \\
\text { on with Abra }\end{array}$ & $\begin{array}{l}\text { e control (sal } \\
\text { ne® group: }{ }^{\circledR} \\
\text { X-PA (25.58 r }\end{array}$ & $\begin{array}{l}\text { e): }{ }^{*} P<0.05,{ }^{* \star} P<0 . \\
<0.05, \& \& P<0.01\end{array}$ & ${ }^{* *} P<0.001$ & \\
\hline
\end{tabular}

\subsection{Blood biochemical test}

Blood biochemical index test showed no significant difference in AST, ALT, UN and CR levels between the four groups (Fig. 12), indicating that Nab-PTX-PA did not have significant adverse effects on liver and kidney functions. Bone marrow suppression toxicity and cardiotoxicity are important indexes for the application of PTX-based preparations. The results demonstrated no significant difference in CK levels between Nab-PTX-PA and NS groups. While CK level was elevated significantly in Abraxane® group (Fig. 12B), suggesting that Nab-PTX-PA did not induce cardiotoxicity at the designed doses. 
Hemocompatibility, histocompatibility and the enhanced antitumor effect of Nab-PTX-PA could be attributed to the palmitic acid modification and targeted sustained.

Table 6

Comparison of blood parameters indicating the anti-tumor effect of Nab-PTX-PA in mouse 4T1 cells $(\overline{\mathrm{x}} \pm \mathrm{s}, n=6)$

\begin{tabular}{|llllll|}
\hline Group & ALT & AST & UN & Crea & CK \\
\cline { 2 - 6 } & $(\mathrm{U} / \mathrm{L})$ & $(\mathrm{U} / \mathrm{L})$ & $(\mathrm{mg} / \mathrm{dL})$ & $(\mu \mathrm{mol} / \mathrm{L})$ & $(\mathrm{U} / \mathrm{L})$ \\
\hline Saline & $42.8 \pm 9.48$ & $150.5 \pm 4.13$ & $25.34 \pm 0.86$ & $32.4 \pm 3.17$ & $623.4 \pm 3.11$ \\
\hline Abraxane® & $42.2 \pm 2.38$ & $152.1 \pm 4.41$ & $20.23 \pm 3.91$ & $31.8 \pm 3.10$ & $676.5 \pm 6.36$ \\
\hline $\begin{array}{l}\text { Nab-PTX-PA } \\
(25.58 \mathrm{mg} / \mathrm{kg})\end{array}$ & $61.7 \pm 2.82$ & $153.4 \pm 5.06$ & $21.59 \pm 2.29$ & $32.6 \pm 3.62$ & $524.6 \pm 6.08$ \\
\hline $\begin{array}{l}\text { Nab-PTX-PA } \\
(51.16 \mathrm{mg} / \mathrm{kg})\end{array}$ & $69.6 \pm 5.27$ & $152.9 \pm 7.85$ & $22.12 \pm 3.19$ & $32.1 \pm 2.55$ & $550.7 \pm 11.53$ \\
\hline
\end{tabular}

\section{Discussion}

In this experiment, Nab-PTX-PA was prepared by using chloroform and anhydrous ethanol as the solvent, emulsified and homogenized under high-pressure homogenization without using the surfactant. The operation process was simple, and the liposolubility of PTX-PA was stronger than PTX. During the preparation process, albumin was not easy denatured at low temperature, and finally the organic solvent was removed by ultrafiltration. PTX-PA was more stable in an amorphous state and not easy to leak during storage, thus improving the stability of the product. The prepared Nab-PTX-PA was spherical and evenly distributed, with a particle size of $87.63 \pm 1.15 \mathrm{~nm}(n=3)$, a single peak, PDI $=0.185 \pm 0.009(n=3)$, and Zeta potential of $-11.70 \pm 0.61 \mathrm{mV}(n=3)$. It was found that the drug loading could be twice large as Abraxane ${ }^{\circledR}(20 \mathrm{mg} / \mathrm{kg})$. The result of the experiment with Nab-PTX-PA in vitro release and the degradation of PTX-PA into PTX showed that Nab-PTX-PA could release PTX-PA from plasma and transform into active mother drug PTX under the action of enzyme ester in vivo, which is consistent with the expectation of the experiment. After conversion to the mother drug, the activity of 2-OH was restored, which provided the possibility to achieve the anti-tumor effect. PTX was Modified to PTX-PA by one step esterification, the more fat-soluble, the stronger it bound within hydrophobic pockets of albumin, and the steric hindrance of the ester group increases, which made hydrolysis difficult, and the main purpose of preparing Nab-PTX-PA was to slow down the release.

The ability of drug uptake by cells is an important index to reflect the efficacy. The results of cell uptake experiments showed that Nab-PTX-PA could be ingested by 4T1 tumor cells and had a potential antitumor effect. The result of cell proliferation toxicity in vitro showed that the Nab-PTX-PA had concentration-dependent toxicity, and the cell proliferation toxicity was significantly lower than that of the 
commercially available Abraxane ${ }^{\circledR}$. On the basis of in vitro experiments, we performed a tissue distribution experiment and a pharmacodynamics study to investigate bone marrow suppression of the testing drugs. The result of the tissue distribution experiment showed that the concentration of PTX metabolized by Nab-PTX-PA increased slowly in the tumor site, which proved that Nab-PTX-PA could be continuously transformed into PTX to increase its accumulation in the tumor site. As a result, the antitumor potential was increased. After intravenous injection of Abraxane ${ }^{\circledR}$, the drug concentration in the liver and kidney was relatively high, and the drug concentration decreased rapidly in various tissues of the mice, and the same trend was also observed in the tumor site, indicating that the time of the anti-tumor action of Abraxane ${ }^{\circledR}$ was shortened after it entered the body. After injection of Nab-PTX-PA into the tail vein, the concentration of PTX-PA distribution was increased in all tissues except the tumor site, indicating a wide range of PTX-PA distribution, but the prodrug itself was not active. So it was speculated that PTX-PA had relatively small damage to the normal organs, and the concentration of metabolized PTX increased gradually in various tissues, with the liver and lung predominating, which is consistent with the general characteristics of tissue distribution of NPs and has proved to have no special toxicity. At the tumor site of the tumor-bearing mice, the metabolic PTX concentration increased gradually, which is more beneficial to the anti-tumor effect in the tumor site for a long time. The results of pharmacodynamic study in vivo showed no significant difference in the anti-tumor effect between Nab-PTX-PA $(25.58 \mathrm{mg} / \mathrm{kg})$ and Abraxane ${ }^{\circledR}(20 \mathrm{mg} / \mathrm{kg})$ groups, and the toxicity of bone marrow suppression was decreased in both groups. In addition, $51.16 \mathrm{mg} / \mathrm{kg}$ Nab-PTX-PA and Abraxane ${ }^{\circledR}(20 \mathrm{mg} / \mathrm{kg})$ had similar myelosuppression toxicity, but the anti-tumor effect of the former was significantly enhanced.

As the volume ratio of organic phase to aqueous phase decreased from 1:9 to 1:22, the particle size also decreased to about $85 \mathrm{~nm}$. Under the action of the emulsifier, the organic phase was dispersed into fine emulsion droplets. The smaller the concentration of the emulison droplets in the dispersed medium, the smaller the relative viscosity will be, and the more uniform the emulsion dispersion, the smaller the chance of agglomeration between emulsions will be. As a result, a relatively stable dispersion system can be formed. However, when the volume ratio decreases to a certain extent, the particle size of NPs would not change much. It is proved that the mass concentration of the carrier material affects the deposition rate of NPs in the process of ball formation. With the increase of the polymer mass concentration, the particle size increases accordingly. After the particle size decreases, it is not easy to be swallowed by the reticular endothelial system as a foreign body, the half-life is prolonged, the rate of clearance from plasma slows down, and the targeting effect is enhanced.

The drug loading and encapsulation efficiency of Nab-PTX-PA are relatively high. It is speculated that the solubility of the PTX itself is poor. After palmitic acid modification, the liposolubility is greatly improved, the LogP value is in the suitable range of $0-3$, which improves the properties of the preparation and makes the drug easy to be absorbed. $\mathrm{Nab}^{T \mathrm{~T}}$ technology uses the cavitation under high shear force to open the sulfhydryl or disulfide bond between albumin, and then cross-links between albumin to form new disulfide bonds, thus preparing the NPs. Because of the low temperature in the preparation process, albumin is not easy to denature. In addition, albumin contains a hydrophobic domain and has a variety of hydrophobic drug binding sites, which can better encapsulate hydrophobic drugs. 
Myelosuppressive toxicity is the main side effect of $A b r a x a n e \AA$, which can cause coagulation dysfunction and increase the risk of infection or even secondary leukemia, thus limiting its clinical use. Blood routine examination of the tumor-bearing mice showed that Nab-PTX-PA $(25.58 \mathrm{mg} / \mathrm{kg})$ could significantly reduce the toxicity of bone marrow suppression. It was speculated that when PTX was prepared into a PTX-PA prodrug, the toxicity of bone marrow suppression would be decreased according to the characteristics of the prodrug. Compared with the commercially available Abraxane $\circledast(20 \mathrm{mg} / \mathrm{kg})$, Nab-PTX-PA (25.58 mg/kg) showed no significant difference in antitumor efficacy but had less myelosuppressive toxicity. Compared with Abraxane ${ }^{\circledR}(20 \mathrm{mg} / \mathrm{kg})$, Nab-PTX-PA $(51.16 \mathrm{mg} / \mathrm{kg})$ had similar myelosuppressive toxicity but its anti-tumor effect was increased significantly. Presumably, Nab-PTX-PA at the same concentration is less toxic than $A b r a x a n e \AA$, which provides a new research idea for the development of PTX preparations.

Nab-PTX-PA (25.58 mg/kg) showed the same anti-tumor effect as the commercial drug Abraxane ${ }^{\circledR}$ $(20 \mathrm{mg} / \mathrm{kg})$ in the tumor-bearing mice, and the anti-tumor effect of $51.16 \mathrm{mg} / \mathrm{kg}$ Nab-PTX-PA was better than that of Abraxane $\AA(20 \mathrm{mg} / \mathrm{kg})$. It is speculated that PTX-PA has high fat solubility, binds more closely to albumin and slowly forms a drug-protein complex in blood. More drugs enter tumor cells through active targeting mediated by gp60-cellar protein-SPARC. Palmitic acid is a fatty acid that can be absorbed as energy by cancer cells, so the more the drug accumulates in the tumor site, the stronger the ability to inhibit tumor growth. Albumin is an endogenous substance with no immunogenicity and toxicity. Modification of PTX with palmitic acid not only reduced the adverse effects of the drug but increased tolerance of the experimental mice to the drug. The particle size of Nab-PTX-PA is about $86 \mathrm{~nm}$, and therefore the drug can penetrate and remain in the tumor site more easily through the EPR effect of the tumor, and exert a better anti-tumor effect. In addition, there may be a metabolic balance between the degradation of Nab-PTX-PA to PTX and the consumption of PTX in mice in vivo. In the tumor site, there may be a large number of metabolic esterases with different degrees of activity. After palmitic acid modification, Nab-PTX-PA is doubly targeted, and under the action of metabolic esterase, the directional release of PTX at the tumor site makes the anti-tumor effect of Nab-PTX-PA more effective. On the basis of the above research, our team will continue to study the tissue distribution, pharmacokinetics and different metabolic esterase activities of Nab-PTX-PA in vivo and try to explain the results of pharmacodynamic evaluation of Nab-PTX-PA in animals at s deeper level.

\section{Conclusion}

In the present study, Given the relationship between HSA, fatty acids, and the tumor microenvironment, this is a potential strategy for drug delivery to cancers that have increased demands for HSA and fatty acids. we constructed a drug delivery system by combining the prodrug technology with albumin NPs to overcome the PTX toxicity, short half-life, fast metabolism and poor water solubility, knowing that it is difficult to prepare albumin NPs. Nab-PTX-PA that we prepared in this study has the advantages of high drug loading, good stability and injectability. The retention time of Nab-PTX-PA at the injection site is more than 40 days. Nab-PTX-PA showed a significant inhibitory effect on tumor growth and metastasis in 4T1 tumor-bearing mice in vivo with low systemic cytotoxicity. In addition, Nab-PTX-PA prepared by the 
$\mathrm{Nab}^{\mathrm{TM}}$ technology has no inert carrier or drug adjuvant with an organic solvent. Compared with the commercially available PTX preparations, Nab-PTX-PA has better physical stability and drug loading. According to the EPR mechanism, Nab-PTX-PA can effectively deliver PTX to the tumor environment. In addition, Nab-PTX-PA improved the pharmacokinetic parameters of PTX and prolonged the half-life of PTX. Compared with other preparations, the dual targeting of Nab-PTX-PA prodrug and albumin also improved the anti-tumor activity and survival rate of animals. To sum up, this Nab-PTX-PA preparation is safe and effective, showing broad application prospects in tumor targeted therapy, and may promote the further development of PTX in practical application.

\section{Abbreviation}


Abbreviations for the whole article

\begin{tabular}{|c|c|}
\hline Abbreviation & Description \\
\hline NPs & Nanoparticles \\
\hline PTX-PA & Paclitaxel Palmitate \\
\hline Nab-PTX-PA & Paclitaxel Palmitate Albumin Nanoparticles \\
\hline PTX & Paclitaxel \\
\hline LCFAs & Long Chain Fatty Acids \\
\hline HSA & Human Serum Albumin \\
\hline cremophor EL & Polyoxyethylene Castor Oil \\
\hline PDI & Polydispersity Index \\
\hline TEM & Transmission Electron Microscopy \\
\hline EE & Encapsulation Efficacy \\
\hline NS & Normal Saline \\
\hline IV & Intravenously \\
\hline WBC & White Blood Cell \\
\hline HGB & Hemoglobin \\
\hline RBC & Red Blood Cell \\
\hline Neut & Neutrophil \\
\hline PLT & Platelet \\
\hline ALB & Albumin \\
\hline TBIL & Total Bilirubin \\
\hline ALT & Alanine Aminotransferase \\
\hline AST & Alanine Aminotransferase \\
\hline CRE & Creatinine \\
\hline UN & Urea nitrogen \\
\hline CK & Creatine Kinase \\
\hline SD & Standard Deviation \\
\hline EPR & Enhanced Permeability And Retention \\
\hline
\end{tabular}

\section{Declarations}




\section{Conflicts of interest}

There are no conflicts to declare.

\section{Acknowledgments}

This study was supported by the National Natural Science Foundation of China (No.81772749, 81872220); Shanghai Rising-Star Program (No.18QB1400400); Shanghai Science and Technology Project of Little Giant (1902HX76600); Shanghai Sailing Program (20YF1412100); Jiaxing Key Laboratory of Oncological Photodynamic Therapy and Targeted Drug Research as the basic public welfare research project of Zhejiang Province (No.LGF18H160034); and Jiaxing Key Laboratory of Oncological Photodynamic Therapy and Targeted Drug Research.

\section{References}

1. Hong W, Kim K, Jung Y, et al. 432 Comparison of Efficiency and Side Effect of Adriamycin and Doxetaxel and Adriamycin, Cyclophosphamide and PTX in Patients with Locally Advanced Breast Cancer Receiving Neoadjuvant Chemotherapy[J]. European Journal of Cancer, 2012, 48(Suppl 1): S172-S173.

2. Webster L, Linsenmeyer M, Millward M, et al. Measurement of cremophor EL following taxol: plasma levels sufficient to reverse drug exclusion mediated by the multidrug-resistant phenotype[J]. J Natl Cancer I, 1993, 85:1685-1690.

3. Duggett NA囚Griffiths LA囚Flatters SJL. PTX-induced painful neuropathy is associated with changes in

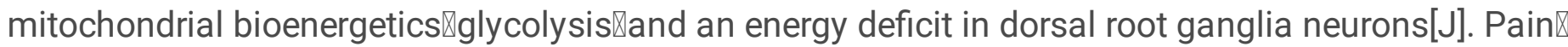
2017,158ه8ه1499-1508.

4. Skwarczynski M, Hayashi Y, Kiso Y. PTX prodrugs: toward smarter delivery of anticancer agents[J]. Journal of Medicinal Chemistry, 2006, 49(25):7253-69.

5. Zenoni M, Maschio S. PTX-based antitumor formulation: US, US20030187062[P]. 2003.

6. Itatani $Y$,Kawada $K$,Yamamoto $T$, et al. Resistance to anti-angiogenic therapy in cancer-alterations to anti-VEGF pathway[J]. International Journal of Molecular Sciences, 2018 ,19(4): 1232.

7. Tai C J,Huang M T,Wu C H, et al. Combination of two targeted medications (bevacizumab plus cetuximab) improve the therapeutic response of pancreatic carcinoma[J].Medicine(Baltimore), 2016, 95(15): e3259.

8. Tai $\mathrm{C}$ J,Wang $\mathrm{H}$,Wang $\mathrm{C} \mathrm{K}$, et al. Bevacizumab and cetuximab with conventional chemotherapy reduced pancreatic tumor weight in mouse pancreatic cancer xenografts[J]. clinical and experimental medicine, 2017, 17(2): 141-150.

9. Yin T, Dong L, Cui B, et al. A toxic organic solvent-free technology for the preparation of PEGylated PTX nanosuspension based on human serum albumin for effective cancer therapy.[J]. International Journal of Nanomedicine, 2015, 10(1): 7397-7412. 
10. Thadakapally R, Aafreen A, Aukunuru J, et al. Preparation and Characterization of PEG-albumincurcumin Nanoparticles Intended to Treat Breast Cancer.[J]. Indian Journal of Pharmaceutical Sciences, 2016, 78(1): 65-72.

11. Maryam Karimia,b , Fatemeh Gheybic , Parvin Zamani, et al.Preparation and characterization of stable nanoliposomal formulations of curcumin with high loading effiffifficacy: In vitro and in vivo anti-tumor study.[J].International Journal of Pharmaceutics,2020, 580.

12. Shahani K, Swaminathan S K , Freeman D, et al. Injectable Sustained Release Microparticles of Curcumin: A New Concept for Cancer Chemoprevention[J]. Cancer Research, 2010, 70(11): 44434452.

13. Salehiabar M, Nosrati H, Javani E, et al. Production of biological nanoparticles from bovine serum albumin as controlled release carrier for curcumin delivery[J]. International journal of biological macromolecules, 2018, 115: 83-89.

14. Yi X, Lian X, Dong J, et al. Co-delivery of pirarubicin and PTX by human serum albumin nanoparticles to enhance antitumor effect and reduce systemic toxicity in breast cancers[J]. Molecular pharmaceutics, 2015, 12(11): 4085-4098.

15. Karimi M, Avci P, Mobasseri R, et al. The novel albumin-chitosan core-shell nanoparticles for gene delivery: preparation, optimization and cell uptake investigation[J]. Journal of nanoparticle research, 2013, 15(5): 1651.

16. Xiong $X Y$, Pan $X$, Tao $L$, et al. Enhanced effect of folated pluronic F87-PLA/TPGS mixed micelles on targeted delivery of PTX[J]. International journal of biological macromolecules, 2017, 103: 10111018.

17. Dou T, Wang J, Han C, et al. Cellular uptake and transport characteristics of chitosan modified nanoparticles in Caco-2 cell monolayers[J]. International journal of biological macromolecules, 2019, 138: 791-799.

18. Chung H J, Kim H J, Hong S T. Tumor-specific delivery of a PTX-loading HSA-haemin nanoparticle for cancer treatment[J]. Nanomedicine: Nanotechnology, Biology and Medicine, 2020, 23: 102089.

19. Pandya A D, Jäger E, Fam S B, et al. PTX-loaded biodegradable ROS-sensitive nanoparticles for cancer therapy[J]. International journal of nanomedicine, 2019, 14: 6269-6285.

20. Li F, Yuan H, Zhang H, et al. Neonatal Fc Receptor ( FcRn) Enhances Tissue Distribution and Prevents Excretion of nab-PTX[J]. Molecular pharmaceutics, 2019, 16(6): 2385-2393.

21. Verco J, Johnston W, Baltezor M, et al. Pharmacokinetic Profile of Inhaled Submicron Particle PTX (NanoPac $\AA$ ) in a Rodent Model[J]. Journal of aerosol medicine and pulmonary drug delivery, 2019, 32(2): 99-109.

22. Gardner E R, Dahut W, Figg W D. Quantitative determination of total and unbound PTX in human plasma following Abraxane treatment[J]. Journal of Chromatography B, 2008, 862(1-2): 213-218.

23. Kaddoumi A, Gill KK, Elfakhri K, et al. Development and qualification of an LC-MS/MS method for investigating the biological implications of micelle entrapped PTX in cell culture and rats[J]. Biomedical Chromatography, 2017, 31(9): e3960. 
24. Kinoshita R, Ishima Y, Chuang V T G, et al. Improved anticancer effects of albumin-bound PTX nanoparticle via augmentation of EPR effect and albumin-protein interactions using S-nitrosated human serum albumin dimer[J]. Biomaterials, 2017, 140: 162-169.

25. Okamoto Y, Taguchi K, Sakuragi M, et al. Preparation, Characterization, and in Vitro/in Vivo Evaluation of PTX-Bound Albumin-Encapsulated Liposomes for the Treatment of Pancreatic Cancer[J]. ACS omega, 2019, 4(5): 8693-8700.

\section{Figures}

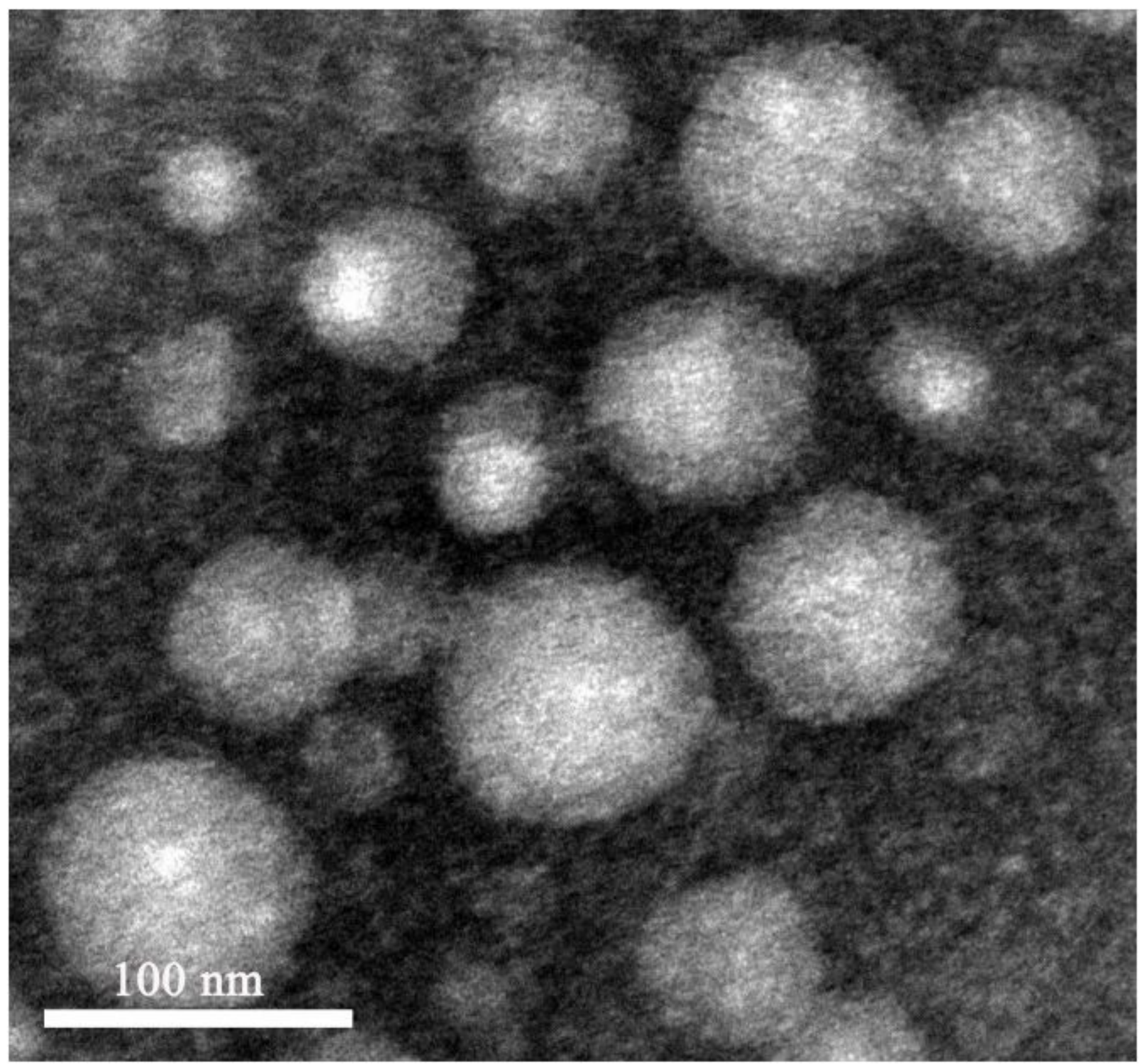

\section{Figure 1}

TEM micrographs of Nab-PTX-PA 

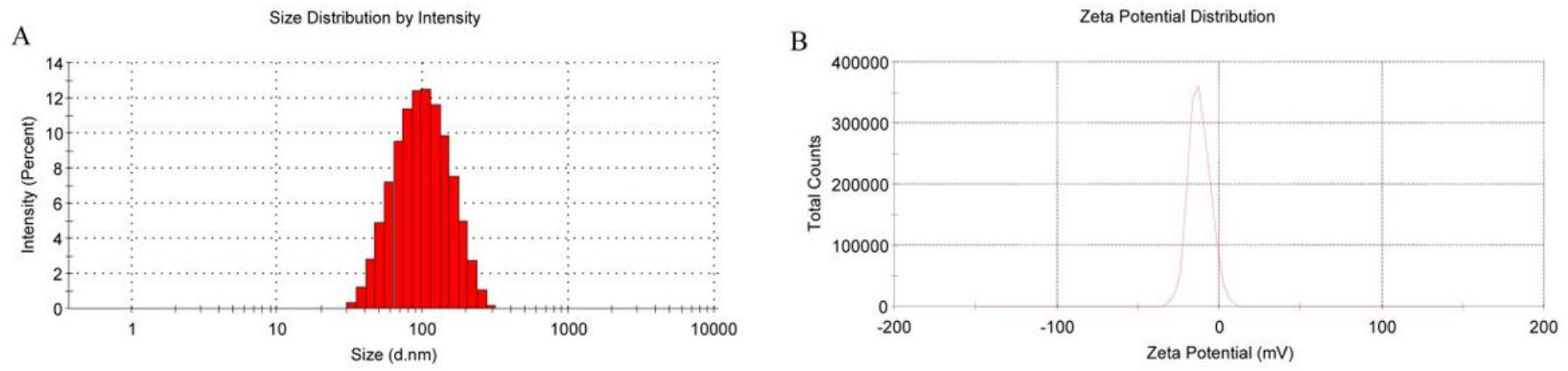

Figure 2

Particle size distribution and zeta potential of Nab-PTX-PA

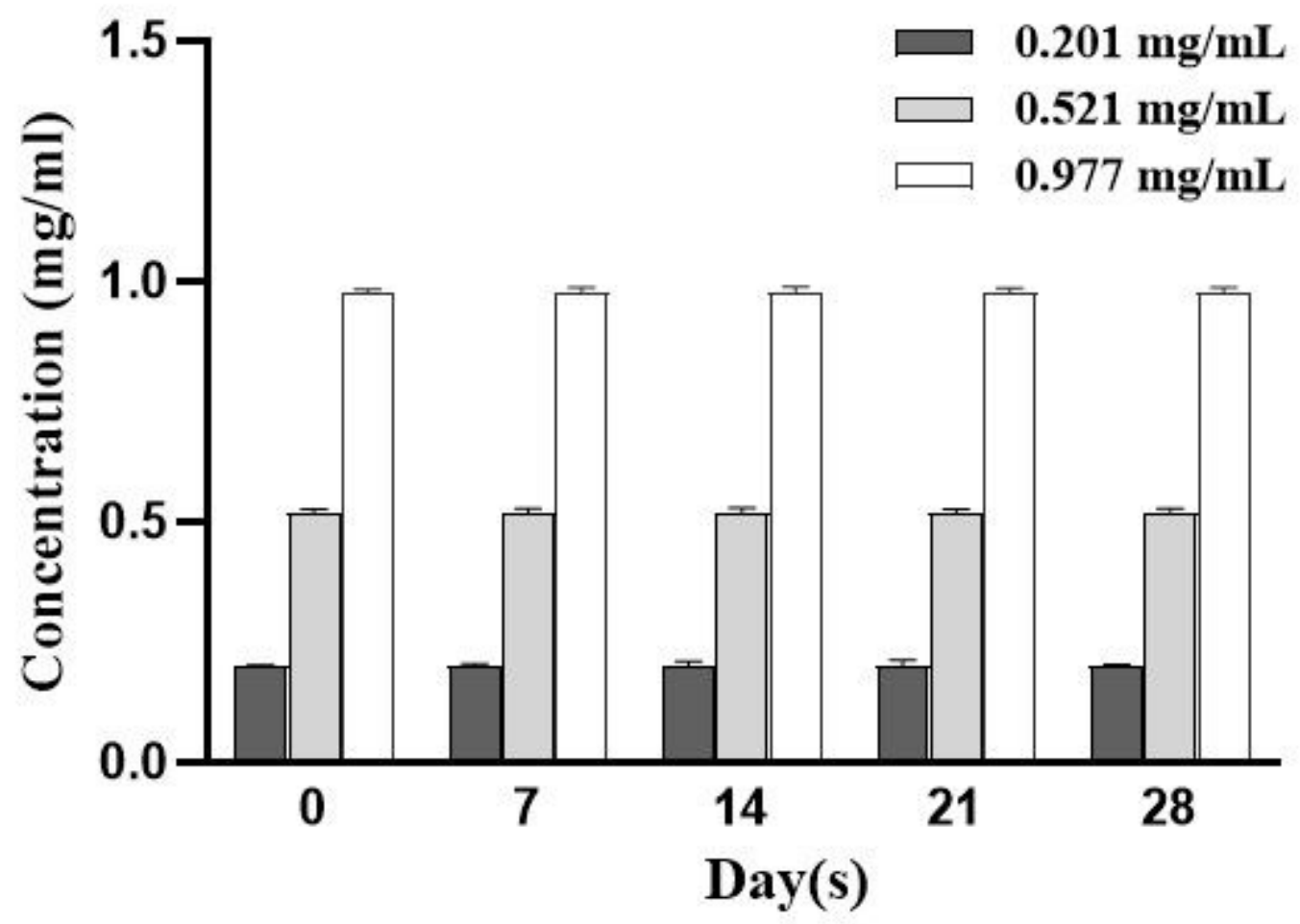

Figure 3

Stability of three PTX-PA solutions of different concentrations 


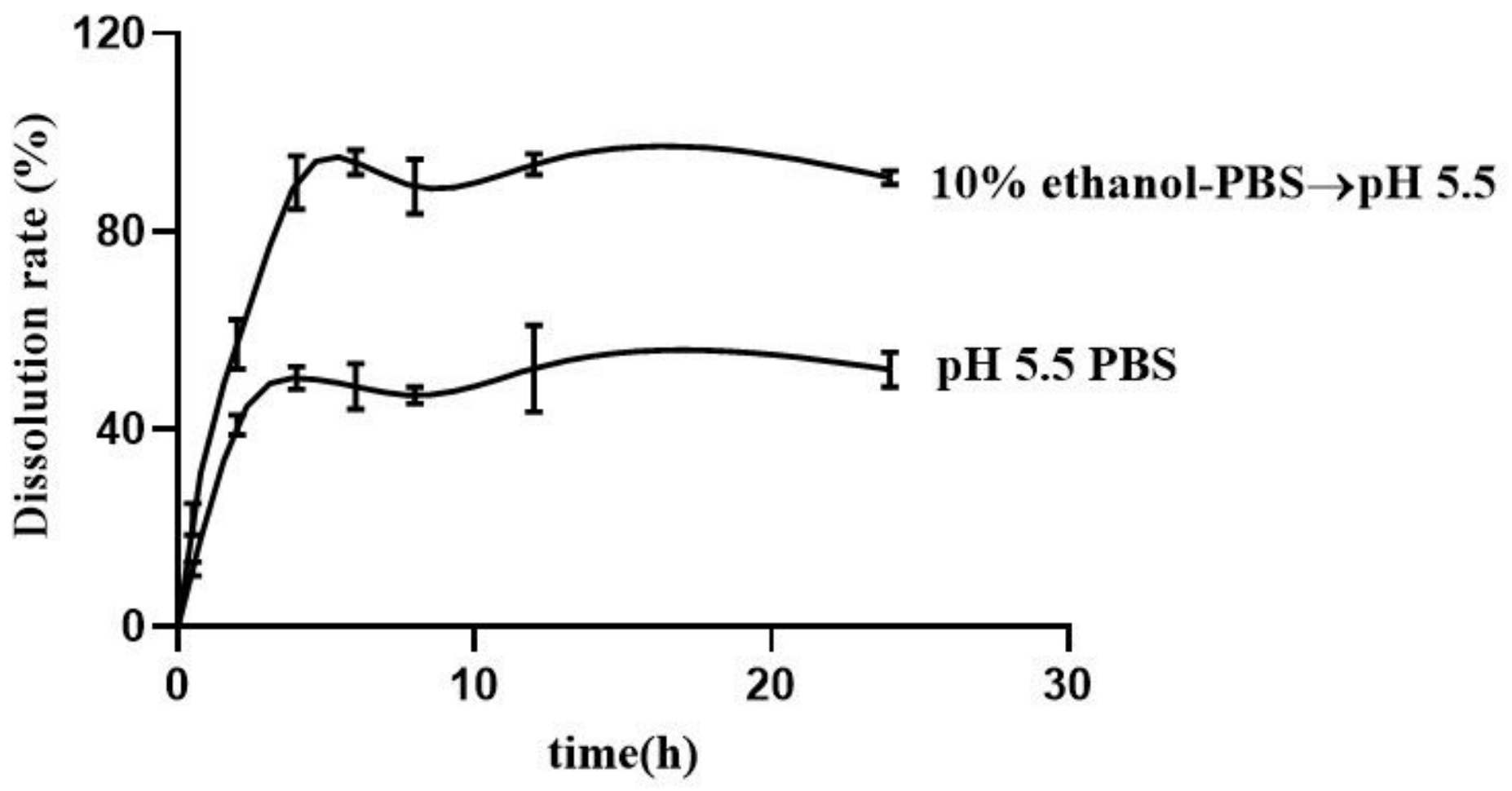

Figure 4

In vitro release of Nab-PTX-PA in different media

$\mathbf{A}$

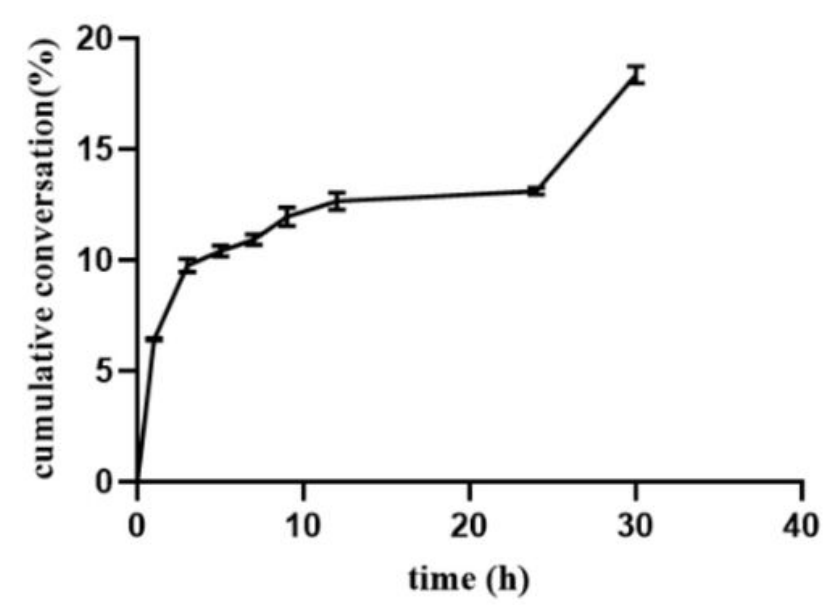

B

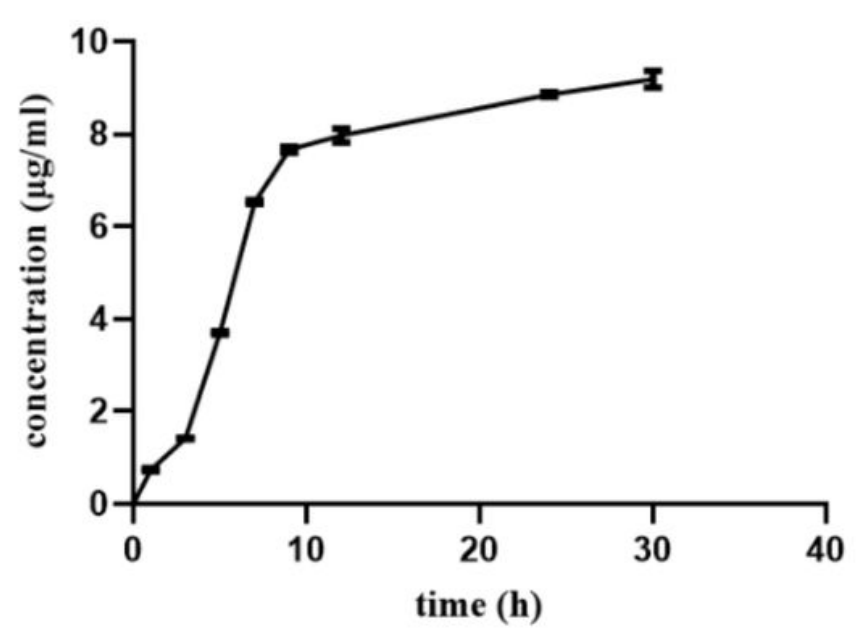

Figure 5

The cumulative conversion curve of Nab-PTX-PA in rat plasma and the converted PTX concentration $\llbracket n=3 \rrbracket$ A: The cumulative conversion curve of Nab-PTX-PA in rat plasma; $B$ : the concentration of PTX 


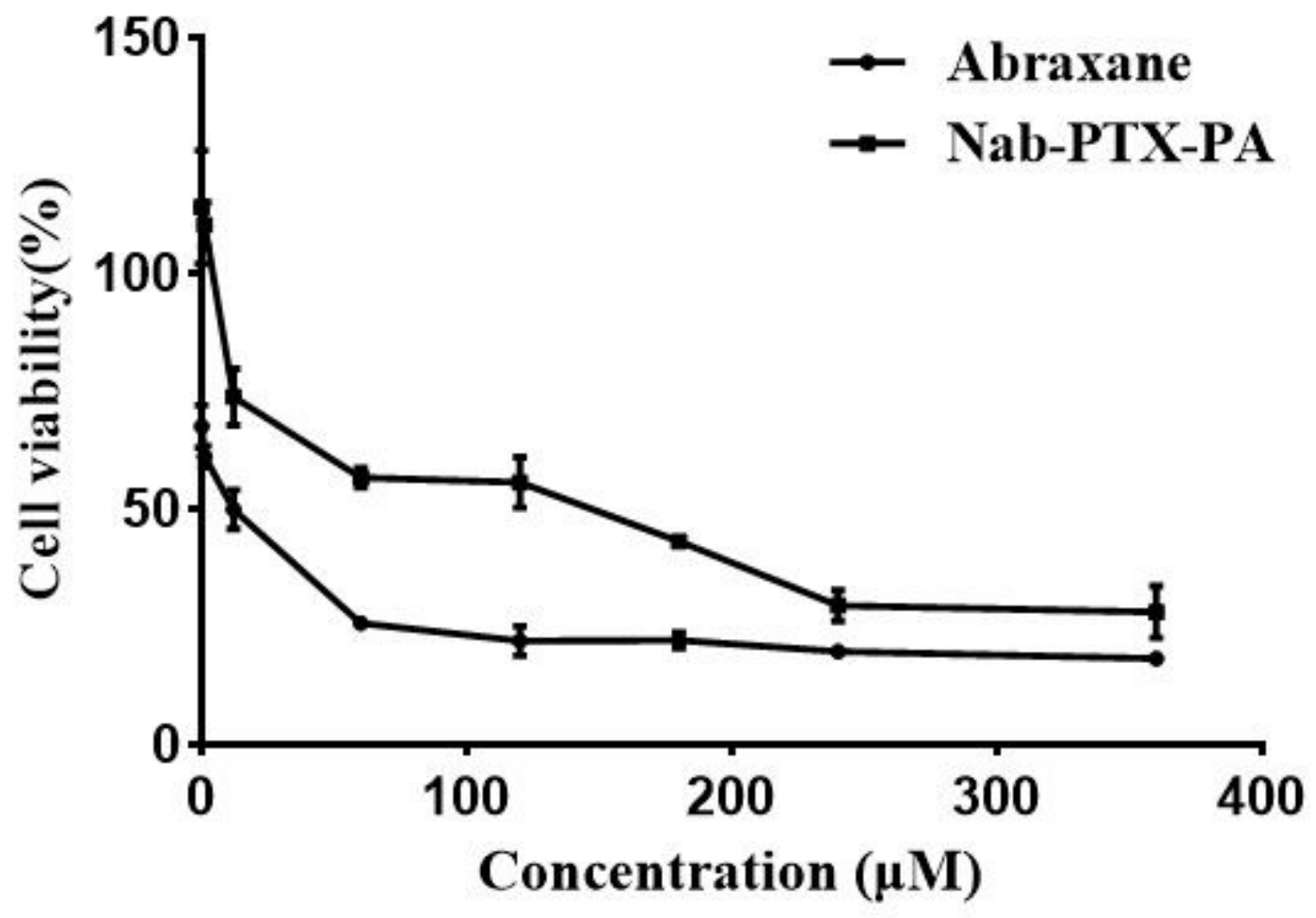

Figure 6

The $4 T 1$ cell survival rate of Abraxane ${ }^{\circledR}$ and Nab-PTX-PA at different concentrations $(n=3)$ 

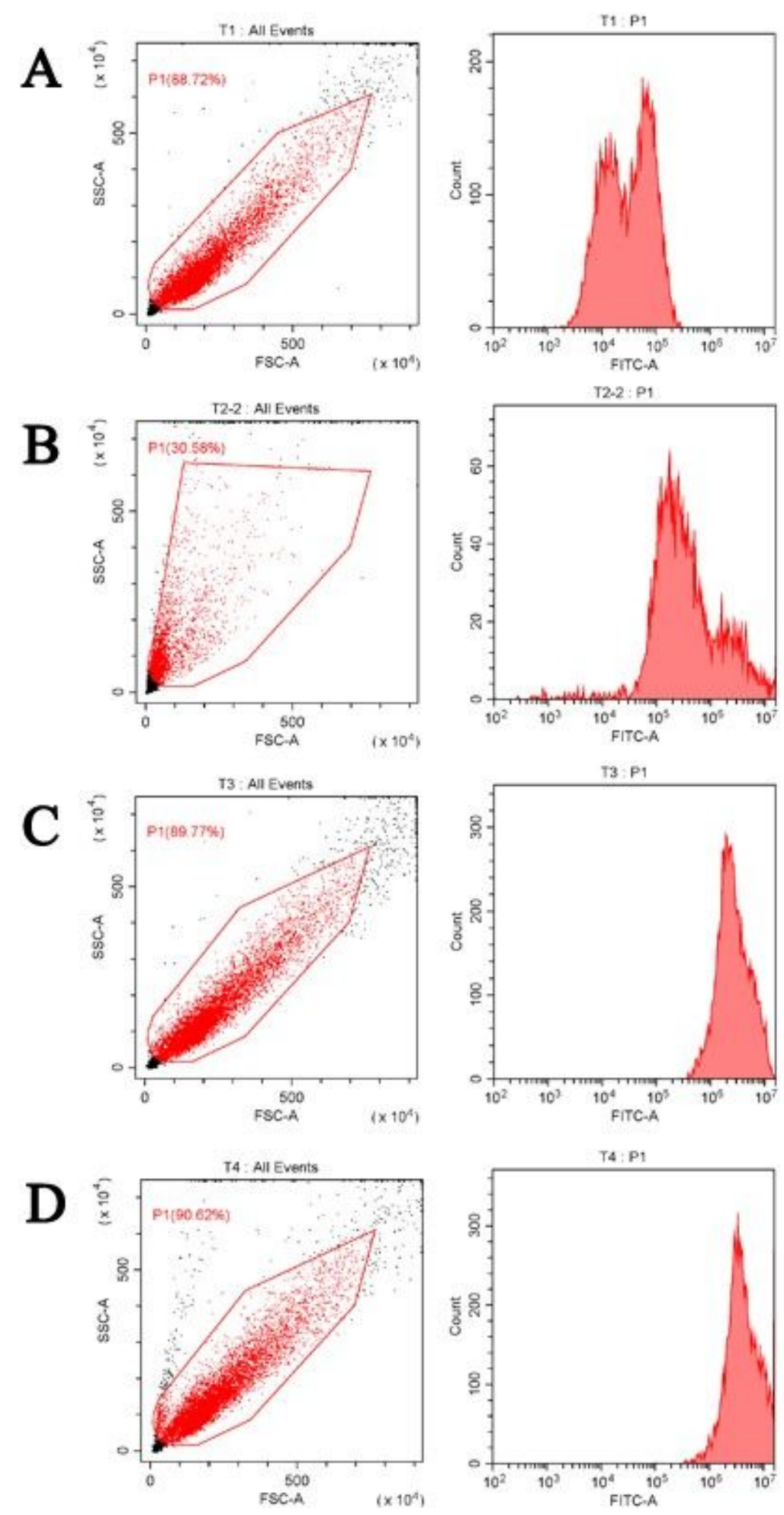

\section{Figure 7}

Cell flow chart of each group A: blank cell group; B: free coumarin group; C: Nab-PTX-PA fluorescence group; D: Abraxane® fluorescence group 

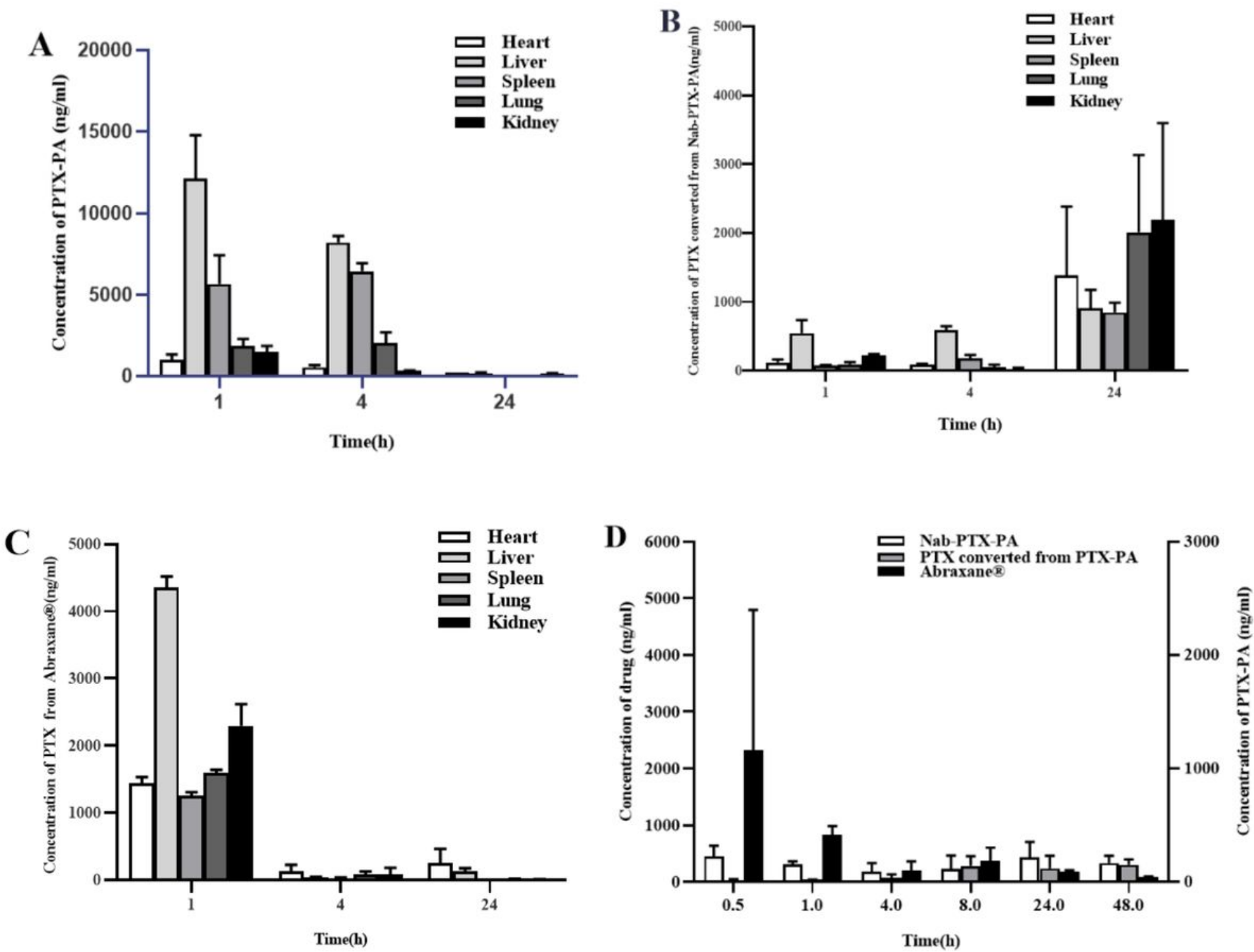

Figure 8

Concentrations of Abraxane ${ }^{\circledR}$ and Nab-PTX-PA in tissues after intravenous injection in 4T1 tumor-bearing ICR mice A: Concentration of Abraxane ${ }^{\circledR}$; B: Concentration of PTX-PA; C: Concentration of PTX converted from PTX-PA; D: Concentration of PTX in tumor 

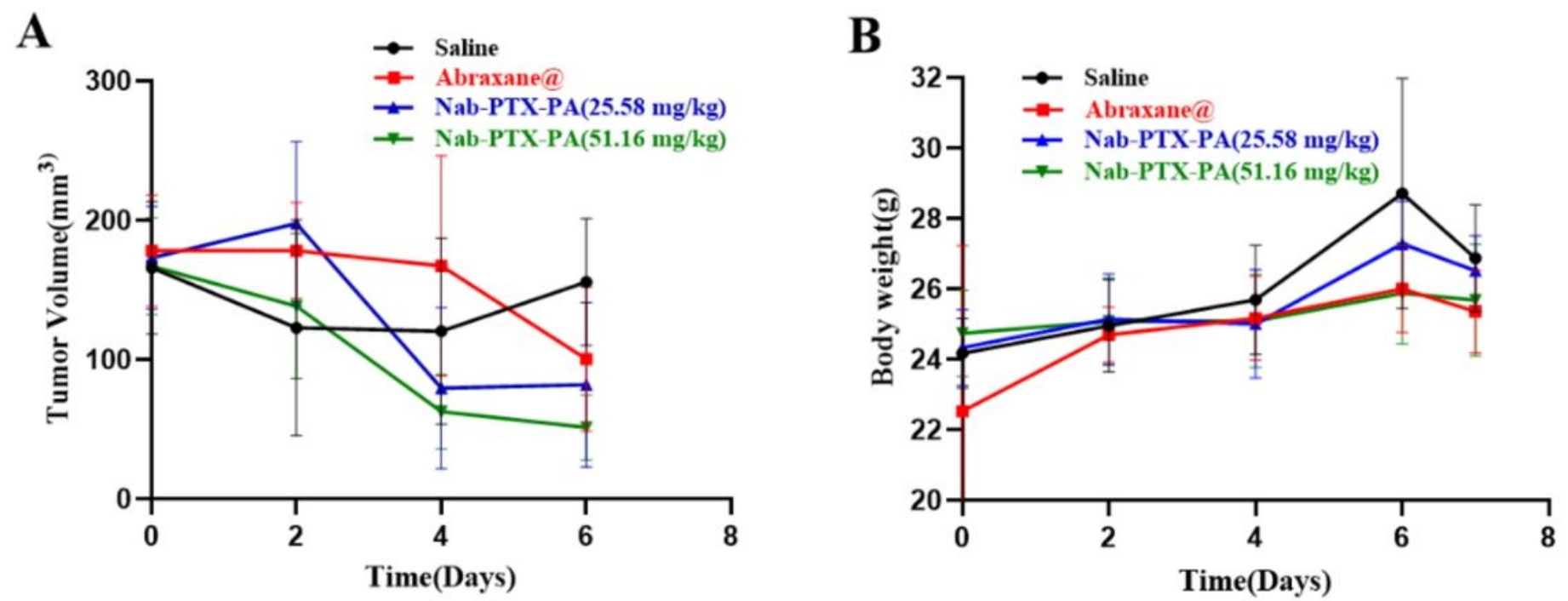

Figure 9

Graphs indicating tumor volume and weight changes in Abraxane ${ }^{\circledR}, \mathrm{Nab}-\mathrm{PTX}-\mathrm{PA}(25.58 \mathrm{mg} / \mathrm{kg})$ and NabPTX-PA (51.16 mg/kg) mouse 4T1 cell models. A: Tumor Volume Change Graph B: Weight Change Line Chart

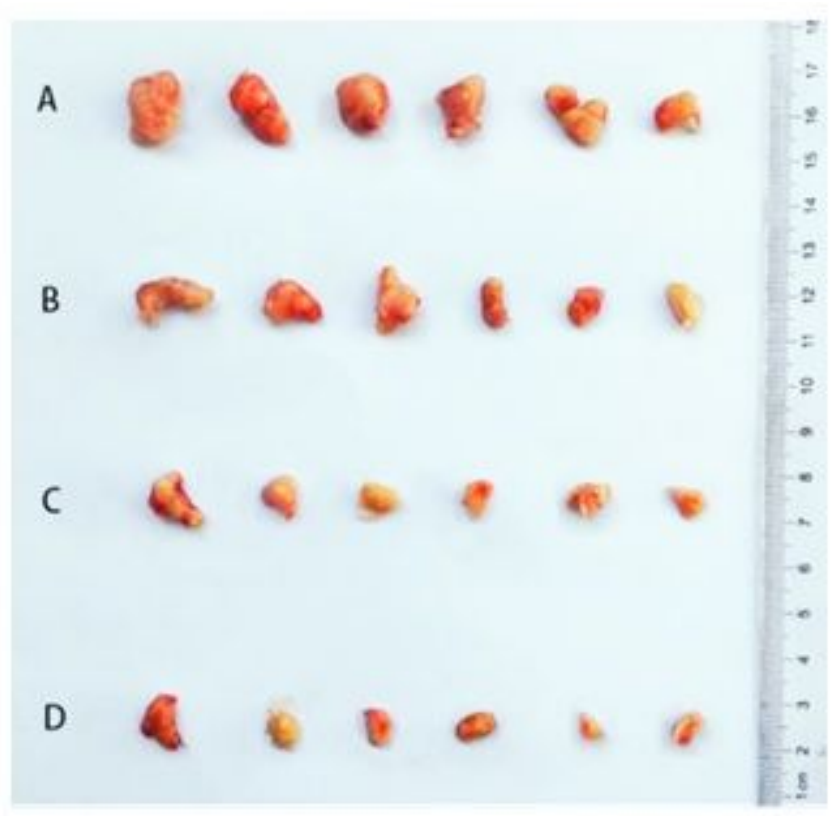

Figure 10

Antitumor effect diagram. A: Normal saline group B: Abraxane® group C: Nab-PTX-PA $(25.58 \mathrm{mg} / \mathrm{kg})$ group D: Nab-PTX-PA (51.16 mg/kg) group 

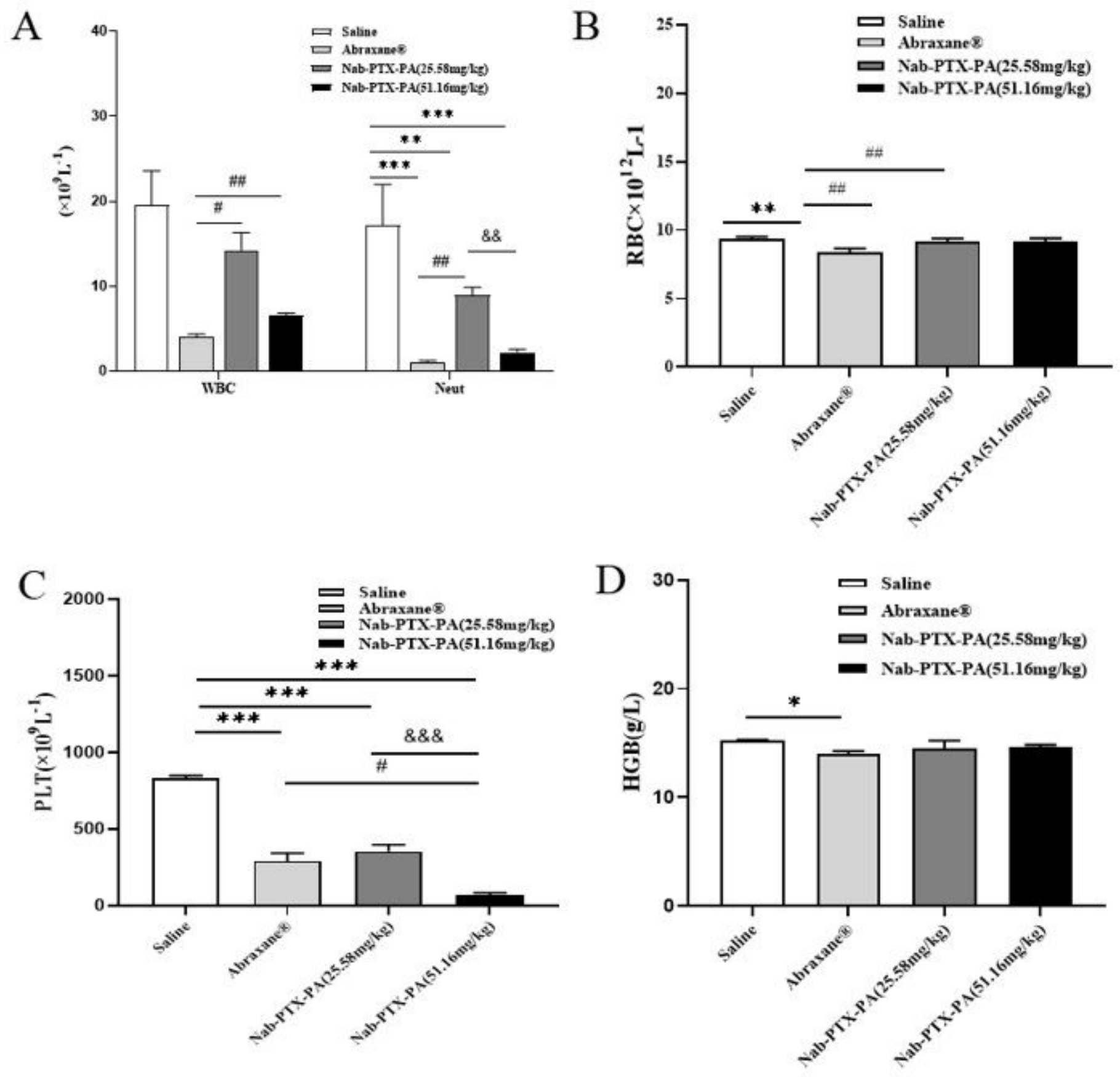

Figure 11

Blood routine examination. A: WBC, Neut (×109 L-1) B: RBC (×1012 L-1) C: PLT (×109 L-1) D: HGB (g/L) 

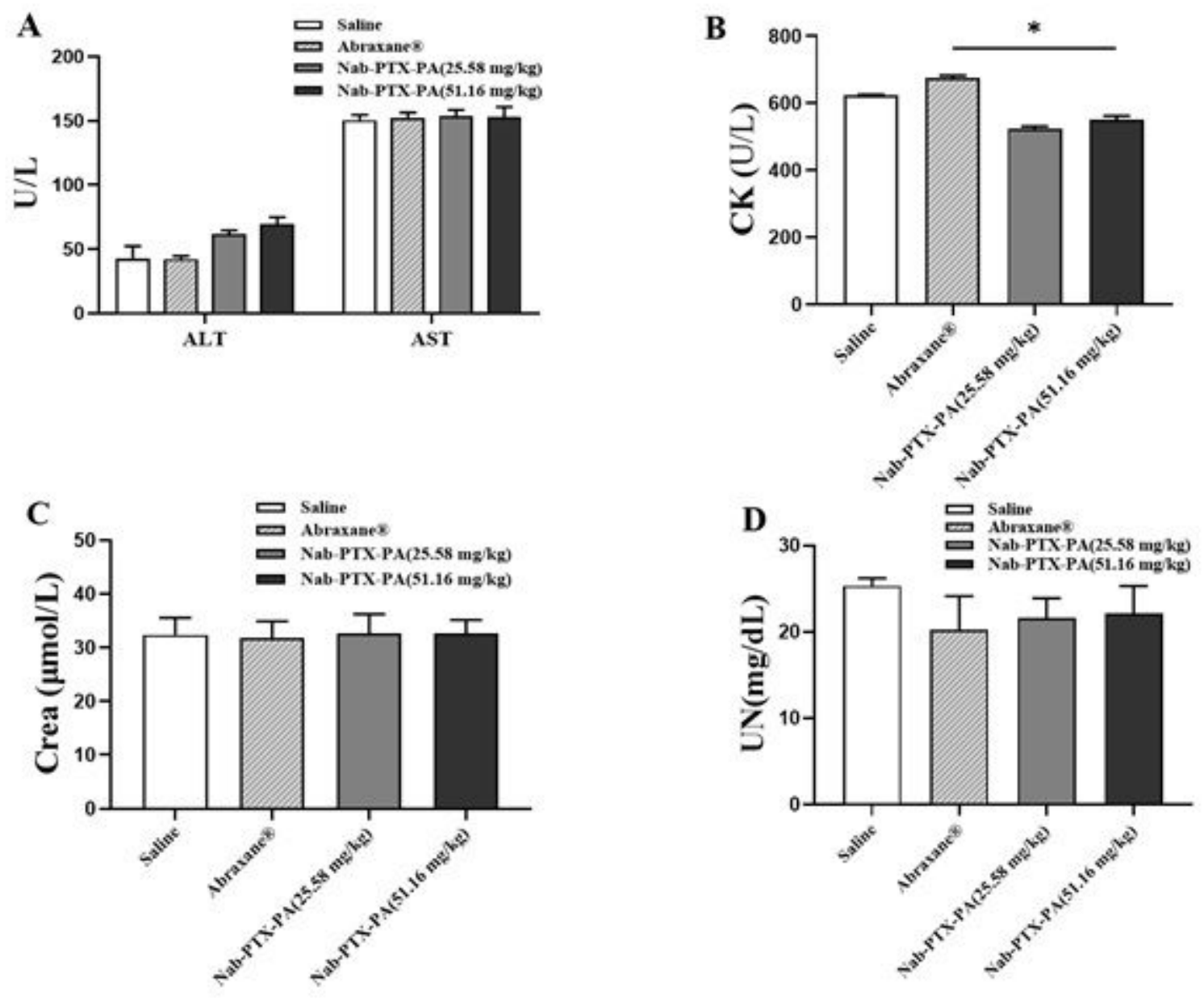

Figure 12

blood biochemical tests. A: ALT, AST (U/ L) B: CK (U/ L) C: Crea ( $\mu \mathrm{mol} / \mathrm{L}) \mathrm{D}$ : UN (mg/dL)

\section{Supplementary Files}

This is a list of supplementary files associated with this preprint. Click to download.

- GraphicalAbstract.pdf 